\title{
THE BROADCASTING OF GRANULAR INSECTICIDES
}

\author{
R. L. TAYLOR \\ Farm Chemicals Company, Mapua, Nelson
}

Summary

This paper discusses briefly the broadcasting, as uniformly as possible, of granular insecticides of size $16 \mathrm{mesh} / \mathrm{in}$. approximately, from ground-based machines and from aeroplanes.

\section{INTRODUCTION}

GranUlAR INSECTICIDES are used in New Zealand mainly to protect pastures against soil insects. Dispersible granules which release powder in rain are used more than baits. Both kinds of granular insecticides need to be broadcast as evenly as possible over the surface of the ground with the lowest possible spreading cost. They should be deposited in a wide swath of uniform density over the central part but tapering off gradually at both edges so as to render lapping less critical.

There is little choice of size in the manufacture of granular insecticides. If the granules are too large there will be too few for adequate ground coverage. If they are too small they will be difficult to spread, will drift too much in wind and will be retained too much on pasture. In practice material is used of size roughly $16 \mathrm{mesh} / \mathrm{in}$. giving 30 to 120 particles/sq. ft when broadcast at 5 to $20 \mathrm{lb} / \mathrm{ac}$. Most of the particles have terminal falling speed between 20 and $30 \mathrm{ft} / \mathrm{sec}$, which is rather less than the optimum for spreading. Spreading equipment which throws the granules must therefore be skilfully designed for sufficiently wide swaths.

\section{MEASURING SPREAD PATTERNS}

Granular materials are sometimes observed on tarmac, on oiled paper or other impervious surfaces. Such observations on the pattern of spread are sometimes useful, but are less valuable than those where samples are collected and measured. Open tins, which must be large to reduce statistical errors, are placed at desired sampling points and the amount of material collected in each is measured. Owing to the variable size of granules it is much better to weigh the samples than to count the particles. It has been found that the bulk volume of each sample provides an estimate of its total weight and insectidal component sufficiently accurate for all studies of spreading. The bulk volume can be found much more quickly than the weight and allows many more observations to be made.

Two kinds of estimates have been made: (1) Sampling in lines across the swath, to provide an estimate of swath pattern and width, and to check uniformity along the line of spread. (2) Sampling at random from many points in the treated area, to indicate errors from all causes including incorrect lapping.

\section{BROADCASTING UNDILUTED GRANULAR INSECTICIDE FROM} GROUND-BASED MACHINES

Very few of the various topdressing machines used to broadcast fertilizer are able to broadcast straight granular insecticide satisfactorily. Many machines cannot sow at a sufficiently low rate. 


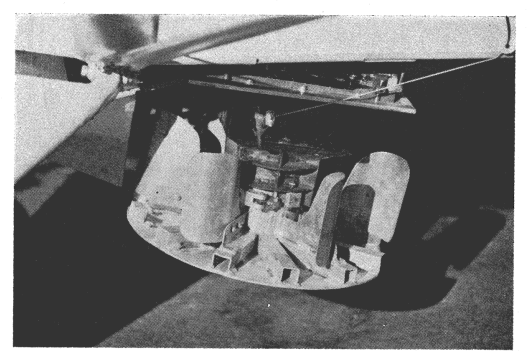

Fig. 1: A spinner spreader fitted beneath Piper 18 aeroplane, which
allows lapping at 50 ft when sowing gran
side side of the spinner is sheltered from slipstream.

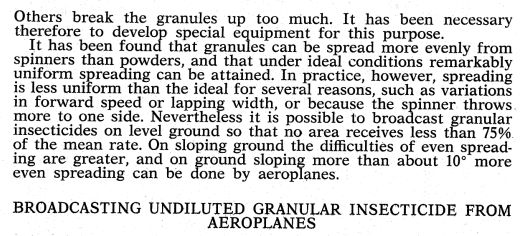
Granules are invariably spread from superphosphate hoppers
and often the same doors are used to meter the flow in which
case the opening gap - only about 33 in. - is critical. Unless the case the opening gap - only about $3 /$ in. - is criticall. Unless the
door opening controls can be freed of backlash it is desirable to
block off some of the width of the doors to render the opening block off some of the width of the doors to render the opening
wider and therefore less critical. With good equipment the flow
out of the hopper is very constant and the rate sown per acre can
be accion After leaving the hopper doors the granules fall in a fairly narrow
track After leaving the hopper doors the granules fall in a fairly narrow
track, and lapping must be done as closely as $20 \mathrm{ft}$. $\mathrm{for}$ good
coverage. It is desirable to direct a proportion of the granles laterally after leaving the doors. This is commonly done by passing
the granules and some of the slipstream through a spreader located

The most effective of these devices used in New Zealand is the
"Swathmaster" which gives good spreading at lap distances of 


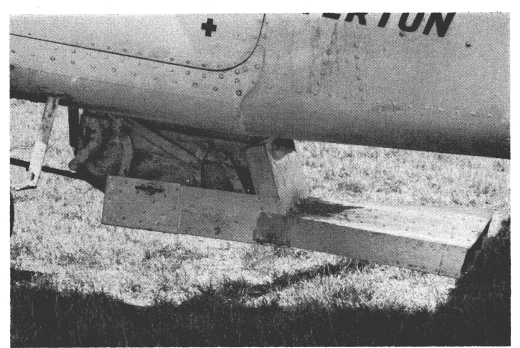

Fig. 2: A small spreader fitted to Cessna 180 aeroplane. Spreaders of
this kind are often used when sowing insecticidal dusts and granules, or grass and clover seed.

50 to $60 \mathrm{ft}$. The Swathmaster has large air drag, cannot be fitted
quickly and is costly. Many a aerial costly.
Motors use small spreaders which are easily
attached and transported and which are very cheaply made. Those attached and transported and which are very cheaply made. Those
studied have been found to widen the swath usefuly but only to studied have been found to widen the swath usefully but only to
the extent of allowing lapping at about 30 th for good spreading.
Their swath pattern is peaked at the centre. It is clear that the Their swath pattern is peaked at the centre. It is clear that the
outer passages of such spreaders should be made to carry a
greater share of the flow of granules, and to discharge in a more lateral direction.
An interesting development is the adaption of spinner spreaders
A aeroplanes. These spreaders are inherently free from peaking to aeroplanes. These spreaders are inherently free from peakin ype a spinner is rim driven by slipstream. It has very low drag
With all types of spreaders the swath does not widen with in With all types of spreaders the swath does not widen with in-
creasing height above $50 \mathrm{ft}$ which is therefore the best height to fleasn easy country. Flying up to $200 \mathrm{ft}$ is normally satisfactory
provided errors of lapping are not excessive. Few pilots however
proper to be able to fly above $100 \mathrm{ft}$ without some increase in in apping errors. Granular rather mores can be spread from suitably equipped
aeroplan spray, and much more evenly
than dust or superphosphate. 'With good spreading equipment and than dust or superphosphate. With good spreading equipment an
skilful flying it is often necessary to collect samples in order to find fault with the spread pattern.
The uniformity of spread begins to deteriorate with 7 to $10 \mathrm{knot}$
of wind but is usually satisfactory up to rather higher wind speeds. SOWING GRANULAR INSECTICIDES MIXED WITH

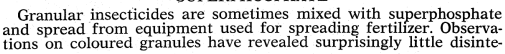
131 
gration of well formed granular material mixed with superphosphate in passing through various topdressers.

Machines with spinners designed and operated for spreading fertilizer or lime are unlikely to throw granular material equally to right or left. It has been observed that the pattern of spread of the granules depends on the properties of both the granules and the fertilizer.

There are obvious economies in spreading fertilizer and insecticide together. The saving is however often offset by mixing costs, back freights and loss of economy in handling bulk fertilizer. Spreading of superphosphate from aeroplanes must be done straight out of the hopper doors because spreaders so far devised are clogged by superphosphate. This necessitates closer lapping than is usually done with superphosphate. All these considerations make the fertilizer mixture with granular insecticides less attractive. 